OPEN ACCESS

Edited by:

Hsien-Yuan Lane,

China Medical University, Taiwan

Reviewed by:

Joshua T. Kantrowitz,

Columbia University, United States

Alessandro Usiello,

Second University of Naples, Italy

*Correspondence:

Ferdinando Nicoletti

ferdinandonicoletti@hotmail.com

Specialty section:

This article was submitted to

Molecular Psychiatry,

a section of the journal

Frontiers in Psychiatry

Received: 13 November 2018

Accepted: 23 January 2019

Published: 14 February 2019

Citation:

Nicoletti F, Orlando R, Di Menna L,

Cannella $M$, Notartomaso $S$,

Mascio G, lacovelli L, Matrisciano F,

Fazio F, Caraci F, Copani A,

Battaglia G and Bruno V (2019)

Targeting mGlu Receptors for

Optimization of Antipsychotic Activity

and Disease-Modifying Effect in

Schizophrenia.

Front. Psychiatry 10:49

doi: 10.3389/fpsyt.2019.00049

\section{Targeting mGlu Receptors for Optimization of Antipsychotic Activity and Disease-Modifying Effect in Schizophrenia}

\author{
Ferdinando Nicoletti ${ }^{1,2 *}$, Rosamaria Orlando ${ }^{1}$, Luisa Di Menna ${ }^{2}$, Milena Cannella ${ }^{2}$, \\ Serena Notartomaso ${ }^{2}$, Giada Mascio ${ }^{2}$, Luisa lacovelli ${ }^{1}$, Francesco Matrisciano ${ }^{3}$, \\ Francesco Fazio ${ }^{2}$, Filippo Caraci ${ }^{4,5}$, Agata Copani ${ }^{4,6}$, Giuseppe Battaglia ${ }^{2}$ and \\ Valeria Bruno ${ }^{1,2}$

\begin{abstract}
${ }^{1}$ Department of Physiology and Pharmacology, Sapienza University of Rome, Rome, Italy, ${ }^{2}$ IRCCS Neuromed, Pozzilli, Italy, ${ }^{3}$ Department of Psychiatry, The Psychiatric Institute, College of Medicine, University of Illinois, Chicago, IL, United States, ${ }^{4}$ Department of Drug Sciences, University of Catania, Catania, Italy, ${ }^{5}$ Oasi Research Institute (IRCCS), Troina, Italy, ${ }^{6}$ Institute of Biostructure and Bioimaging, National Research Council, Catania, Italy
\end{abstract}

Metabotropic glutamate ( $\mathrm{mGlu}$ ) receptors are considered as candidate drug targets for the treatment of schizophrenia. These receptors form a family of eight subtypes (mGlu1 to -8 ), of which mGlu1 and -5 are coupled to $G_{\mathrm{q} / 11}$, and all other subtypes are coupled to $\mathrm{G}_{\mathrm{i} / \mathrm{o}}$. Here, we discuss the possibility that selective ligands of individual mGlu receptor subtypes may be effective in controlling the core symptoms of schizophrenia, and, in some cases, may impact mechanisms underlying the progression of the disorder. Recent evidence indicates that activation of mGlu1 receptors inhibits dopamine release in the meso-striatal system. Hence, selective positive allosteric modulators (PAMs) of mGlu1 receptors hold promise for the treatment of positive symptoms of schizophrenia. mGlu5 receptors are widely expressed in the CNS and regulate the activity of cells that are involved in the pathophysiology of schizophrenia, such as cortical GABAergic interneurons and microglial cells. mGlu5 receptor PAMs are under development for the treatment of schizophrenia and cater the potential to act as disease modifiers by restraining neuroinflammation. mGlu2 receptors have attracted considerable interest because they negatively modulate $5-\mathrm{HT}_{2 \mathrm{~A}}$ serotonin receptor signaling in the cerebral cortex. Both mGlu2 receptor PAMs and orthosteric mGlu2/3 receptor agonists display antipsychotic-like activity in animal models, and the latter drugs are inactive in mice lacking mGlu2 receptors. So far, mGlu3 receptors have been left apart as drug targets for schizophrenia. However, activation of mGlu3 receptors boosts mGlu5 receptor signaling, supports neuronal survival, and drives microglial cells toward an antiinflammatory phenotype. This strongly encourages research of mGlu3 receptors in schizophrenia. Finally, preclical studies suggest that mGlu4 receptors might be targeted by novel antipsychotic drugs, whereas studies of mGlu7 and mGlu8 receptors in animal models of psychosis are still at their infancy.

Keywords: metabotropic glutamate receptors, schizophrenia, positive allosteric modulator, development of cortical interneurons, receptor cross-talk 


\section{BACKGROUND}

In spite of the continuous development of "monoaminergic" antipsychotic agents, drug treatment of schizophrenia remains suboptimal. Current second-generation antipsychotic drugs include drugs with different affinity for dopamine and serotonin receptor subtypes, such as clozapine, olanzapine, quetiapine, asenapine, ziprasidone, lurasidone, risperidone, paliperidone, iloperidone, aripiprazole, cariprazine, and brexpiprazole. These drugs display good therapeutic efficacy against positive symptoms of schizophrenia and their use may slow the progression of brain atrophy (as opposed to first generation antipsychotics) (1). However, a significant proportion of patients affected by schizophrenia is refractory to medication, and a prophylactic use of these agents (i.e., their use prior to the first episode of psychosis) is limited by class-related adverse effects, such as sedation, weight gain, and anticholinergic effects. In addition, none of the first- or second-generation antipsychotics is effective in improving cognitive dysfunction associated with schizophrenia, with the possible exception of clozapine, which is considered as a second- or third-line drug because of serious safety concerns.

Thus, there is an urgent need for new safer antipsychotic agents acting at new targets that lie at the core of the pathophysiology of schizophrenia. A new Molecular Psychiatry article entitled "mGluR5 hypofunction is integral to glutamatergic dysregulation in schizophrenia" (2) is one point of arrival of years of extensive research linking metabotropic glutamate (mGlu) receptors to the pathophysiology and treatment of schizophrenia. This article shows that mGlu5 receptor signaling is blunted in the dorsolateral prefrontal cortex (DLPFC) of individuals affected by schizophrenia (2).

mGlu5 is one of the eight mGlu receptor subtypes that are traditionally subdivided into three groups on the basis of their amino acid sequence, pharmacological profile, and signal transduction mechanisms in heterologous expression systems. Group I includes mGlu1 and mGlu5 receptors, which are coupled to $\mathrm{G}_{\mathrm{q} / 11}$ proteins. Group II (mGlu2 and mGlu3) and group III (mGlu4, mGlu6, mGlu7, and mGlu8) mGlu receptors are all coupled to Gi/o proteins (3). This classification is universally accepted but incomplete from a functional standpoint. Native mGlu receptors activate multiple transduction pathways in a cell-and context-dependent fashion, and numerous subtypeselective biased ligands have been developed. For example, mGlu5 receptors are physically and functionally linked to NMDA receptors in most of the CNS synapses, but there are biasedpositive allosteric modulators (PAMs) of mGlu5 receptors that enhance mGlu5 receptor function without recruiting NMDA receptors $(4,5)$. There are also dogmas in the mGlu field that have been recently challenged. For example, mGlu3 receptors are generally considered as presynaptic receptors that function to restrain neurotransmitter release. In contrast, recent evidence indicates that mGlu3 receptors are also present in postsynaptic elements, where they boost mGlu5 receptor signaling (6). mGlu3 and mGlu5 receptors synergize to induce long-term depression (LTD) in the mouse PFC, and mGlu3-saturating LTD requires the activation of mGlu5 receptors (6). This receptor-receptor interaction may be relevant to the pathophysiology and treatment of schizophrenia (see below).

mGlu receptors were discovered in the mid eighties $(7,8)$, but no mGlu receptor ligands are currently available for clinical use in spite of more than 30 years of extensive research. In our opinion, schizophrenia and Parkinson's disease are the two disorders in which the mGlu research will first translate into the clinic. In section mGlu2 receptors and schizophrenia: to be or no to be? we will comment on a series of clinical studies in which pomaglumetad, the prodrug of the mGlu2/3 receptor agonist, LY404039, has been tested in patients affected by schizophrenia. Although pomaglumetad is no longer under clinical development, these studies attracted more and more interest on mGlu receptors in schizophrenia. It is generally believed that the activity of LY404039 in preclinical models and in subgroups of patients affected by schizophrenia is mediated by the activation of mGlu2 receptors. Here we will challenge the $\ll$ mGlu2-centric $\gg$ hypothesis of schizophrenia suggesting that mGlu3 receptors might be at least as valuable as $\mathrm{mGlu} 2$ receptors as condadate drug targets for schizophrenia. mGlu2 and mGlu3 receptors show important differences in the expression and function in the tripartite synapsis (pre- and postsynaptic elements, and astrocytes), and modulate the activity of microglial cells in an opposite fashion. We will also discuss the rationale behind the development of mGlu5 receptor PAMs and the attractive possibility that mGlu3 receptor agonists or PAMs might produce disease modifying effects in schizophrenia. Finally, we will comment on the attractive possibility that activation of mGlul receptors represents a valuable strategy in the treatment of positive symptoms of schizophrenia, and we will conclude with the discussion of a new set of evidence suggesting that mGlu4 receptors are also candidate drug targets for schizophrenia.

\section{METHODS}

We searched for the following terms on Pubmed: metabotropic glutamate receptors and schizophrenia, metabotropic glutamate receptors and psychosis, metabotropic glutamate receptors and neurodeveloment, metabotropic glutamate receptors and CNS development, metabotropic glutamate receptors and network activity.

\section{TARGETING mGlu5 AND mGIU3 RECEPTORS TO CORRECT NEURODEVELOPMENTAL ALTERATIONS ASSOCIATED WITH SCHIZOPHRENIA}

A large body of evidence suggests that schizophrenia is a neurodevelopmental disorder in which cortical interneurons become dysfunctional as a result of genetic alterations or environmental challenges occurring in the perinatal period. There are at least four processes that characterize the development of cortical GABAergic interneurons: (i) the biochemical specification into different cell types, of which those containing parvalbumin (PV) or somatostatin (SSt) 
are the most numerous; (ii) the correct matching between interneurons and pyramidal neurons (9); (iii) the GABA shift from excitatory into inhibitory driven by the expression of the potassium-chloride symport, KCC2 in mature neurons (10); and (iv) the formation of perineuronal nets (PNNs), which surround $\mathrm{PV}^{+}$interneurons at the offset of the critical temporal windows of developmental plasticity $(11,12)$. The molecular events that drive these processes are only partially elucidated. Schizophrenia is associated with a dysfunction of $\mathrm{PV}^{+}$(basket and chandelier) and other populations of interneurons, with a resulting defect in network oscillations underlying cognitive functions (13) (Figure 1). In addition, several lines of evidence suggest that formation of PNNs is altered in the PFC of patients affected by schizophrenia (14-16). What may link mGlu3 and mGlu5 receptors to these processes is the evidence that the expression of both receptors is high in the early postnatal development, and then progressively declines to reach adult levels after weaning (17). One of the first observations associated with the discovery of mGlu receptors was that $\mathrm{mGlu}$ receptor-mediated polyphosphoinositide (PI) hydrolysis (a biochemical process leading to intracellular $\mathrm{Ca}^{2+}$ mobilization and activation of protein kinase C) is dramatically high in the cerebral cortex and other brain regions during the early 7-9 days of postnatal life, and declines afterwards (8). This robust PI response is mediated by mGlu5 receptors, which are heavily expressed early after birth even in cells that lack mGlu5 receptors in the adult life, such as cerebellar Purkinje cells (18). An unexpected finding was that a large component of mGlu5-mediated PI hydrolysis in the developing PFC was lost in $\mathrm{mGlu} 3^{-/-}$mice, and, therefore, required the endogenous activation of mGlu3 receptors (6). In contrast, mGlu5 receptor-mediated PI hydrolysis was intact in $\mathrm{mGlu}^{-/-}$mice (6). Interestingly, expression of mGlu2 receptors in the cerebral cortex is low in the early postnatal life and increases afterwards (as opposed to expression of mGlu3 and mGlu5 receptors) (17).

Which (if any) of the neurodevelopmental processes taking place early after birth is/are driven by the combined activation of mGlu3 and mGlu5 receptors? This question is starting to be investigated. A reduction in the transcript and protein levels of PV, SSt, GAD-65, GAD-67, Reelin, and AMPA and NMDA receptor subunits has been reported in the PFC of adult mGlu5 ${ }^{-/-}$mice (19). In mGlu3 ${ }^{-/-}$mice we found changes in biochemical markers of cortical GABAergic interneurons during the first 4 weeks of postnatal development, which were not seen in

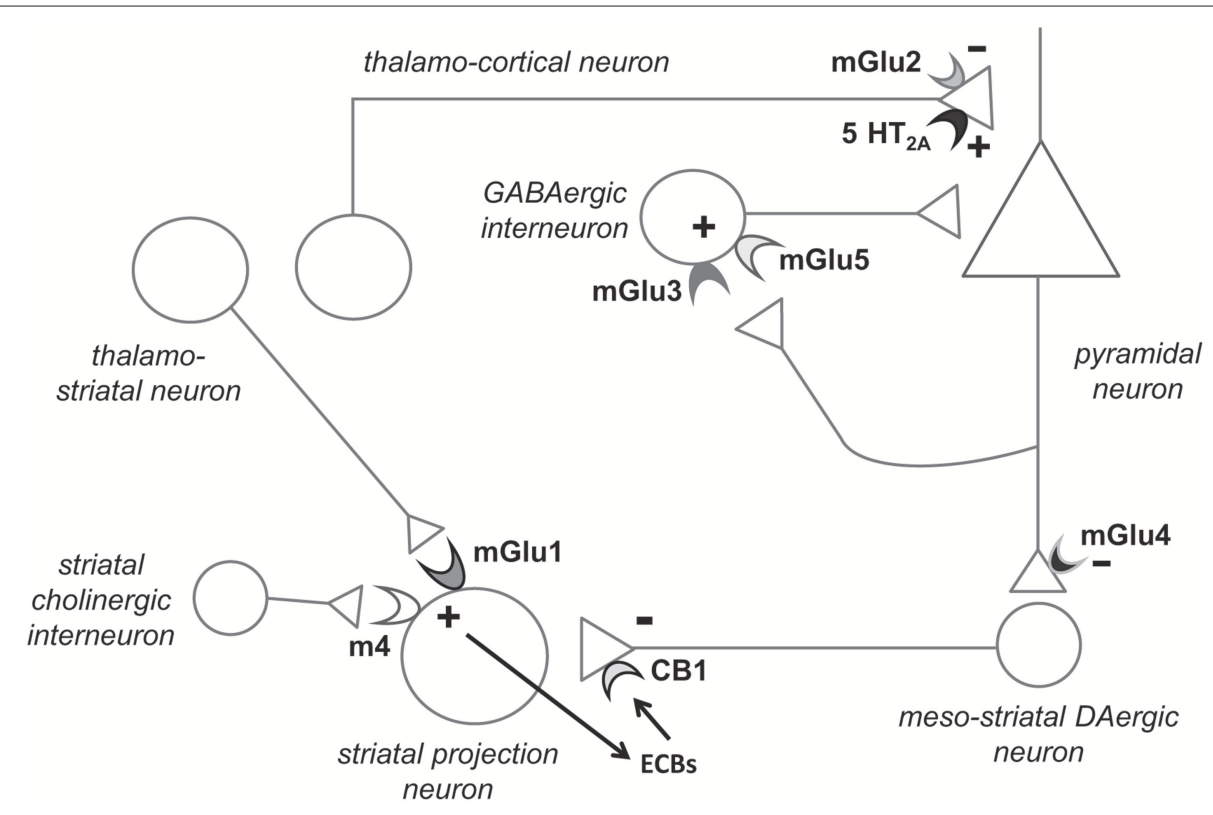

FIGURE 1 | Hypothetical model highlighting the potential role of individual mGlu receptor subtypes in the pathophysiology and treatment of schizophrenia. Presynaptic mGlu2 receptors negatively modulate $5-\mathrm{HT}_{2 \mathrm{~A}}$ receptor signaling, and their activation restrains glutamate release at synapses between thalamo-cortical neurons and cortical pyramidal neurons (see chapter 6). mGlu5 receptors are found in both pyramidal neurons and interneurons (shown here) and functionally interact with NMDA receptors. mGlu5 receptor PAMs are under development for the treatment of schizophrenia (see chapter 4). Recent evidence indicates that mGlu3 receptor activation boost mGlu5 receptor signaling, and, therefore, selective mGlu3 receptor agonists or PAMs should be tested in preclinical models predictive of antipsychotic activity (chapter 3). The functional cross-talk between mGlu3 and mGlu5 receptors has been shown in pyramidal neurons (6). We speculate that the two receptors also interact in GABAergic interneurons, but this remains to be demonstrated. mGlu1 receptors and type-4 muscarinic cholinergic receptors (M4) interact in stimulating the production of endocannabinoids (ECBs) in striatal projection neurons. ECBs activate presynaptic CB1 receptors, thereby reducing dopamine (DA) release from meso-striatal terminals. Hence, mGlu1 receptor PAMs might be effective in improving positive symptoms in schizophrenia (chapter 5). Finally, mGlu4 receptor agonists/PAMs are effective in animal models that are predictive of antipsychotic activity. mGlu4 receptors might act to reduce glutamate release from excitatory nerve endings of pyramidal neurons and through other mechanisms. Not shown here: activation of mGlu3 and mGlu5 receptors may restrain neuroinflammation by driving microglia toward an antinflammatory phenotype, and activation of mGlu3 receptors stimulates the production of neurotrophic factors in astrocytes (see chapters 3 and 4). 
mGlu2 $2^{-/-}$mice (20). These findings suggest that the functional partnership between mGlu3 and mGlu5 receptors may be instrumental for the biochemical and functional specialization of cortical GABAergic interneurons. An attractive hypothesis is that the two receptors may also serve to regulate the numeric balance between pyramidal neurons and GABAergic interneurons in the developing cerebral cortex. An elegant article by Prof. Oscar Marin and his Associates (9) demonstrates that the balanced network between excitatory and inhibitory cortical neurons becomes established through mechanisms of activity-dependent cell death and survival, with the decrease in the total number of pyramidal neurons preceding the decrease in the number of interneurons in the first few days of postnatal life. Surviving interneurons are those that are innervated by pyramidal cells because synaptic excitation enhances the activity of the phosphatidylinositol-3-kinase (PI3K) pathway by suppressing the expression of the PI3K negative regulator, phosphatase and tensin homolog PTEN (9). Both mGlu3 and mGlu5 receptors may signal through the activation of the PI3K pathway (3), and we are currently examining whether genetic and pharmacological manipulation of the two receptors alters the expression of total and phosphorylated PTEN in the developing cerebral cortex. Another interesting area of investigation is whether mGlu5 and mGlu3 receptors regulate KCC2 expression and GABA responses in pyramidal cells during postnatal development. Changes in cortical and cerebellar KCC2 levels were found in mice lacking mGlu3 and mGlu5 receptors, respectively $(20,21)$.

How all this can be relevant to the pathophysiology and experimental treatment of schizophrenia? Cell-specific deletion of mGlu5 receptors in $\mathrm{PV}^{+}$neurons in mice results into a behavioral phenotype modeling schizophrenia, characterized by spontaneous hyperactivity, and defects in pre-pulse inhibition and long-term memory (22). A psychotic-like phenotype was also observed in mice lacking mGlu3 receptors $(23,24)$. Wang et al. (2) found that mGlu5 receptor signaling was largely reduced in the post-mortem DLPFC of individuals affected by schizophrenia, as shown by tyrosine hyperphosphorylation (leading to receptor desensitization), reductions in receptor coupling to $\mathrm{G}_{\mathrm{q} / 11}$, Homer, and $\mathrm{PI} 3 \mathrm{~K}$, and reduced receptor association with adaptor and scaffolding proteins, such as RGS4, norbin, Preso 1 and tamalin. Remarkably, the reduced signaling of mGlu5 receptors disrupted the physiological interplay between mGlu5 and NMDA receptors in the DLPFC of individuals affected by schizophrenia (2). Abnormalities in mGlu3 receptor dimerization have also been reported in the frontal cortex of individuals affected by schizophrenia (25). Polymorphic variants of GRM3 (the gene encoding for the mGlu3 receptor) have been consistently associated with schizophrenia (26-37), and genetic alterations of GRM5 have also been linked to schizophrenia (38).

We hypothesize that, in schizophrenia, a reduced expression and/or activity of mGlu3 and mGlu5 receptors may have a strong impact on the maturation of cortical GABAergic interneurons leading to a permanent alteration of network activity in the frontal cortex. If turned to be correct, this hypothesis raises the interesting possibility that a pharmacological intervention with mGlu3 or mGlu5 receptor PAMs early after birth may restore the correct developmental trajectory rescuing the pathological phenotype. This is a testable hypothesis in animal models, but translation to humans is an extremely difficult task for ethical and practical reasons. Regardless of any potential therapeutical application, defining the precise role of mGlu3 and mGlu5 receptors in neuronal development will give an answer to an intriguing question raised since the discovery of mGlu receptors: why mGlu receptor-mediated PI hydrolysis is so large in the early postnatal life (much larger than PI hydrolysis mediated by any other receptor coupled to $\mathrm{G}_{\mathrm{q} / 11}$ ) and progressively declines afterwards?

Another potential link between mGlu5 receptor signaling and schizophrenia is suggested by the evidence that the endogenous D-amino acid, D-aspartate, has a great efficacy in stimulating PI hydrolysis in cortical or hippocampal slices prepared from 8-9 day-old rats, and its action is largely mediated by mGlu5 receptors (39). D-Aspartate levels are reduced in the dorsolateral prefrontal cortex of patients affected by schizophrenia as a result of an enhanced activity of the catabolic enzyme, D-aspartate oxidase $(40,41)$. In addition, the antipsychotic drug, olanzapine, enhances glutamate release in the prefrontal cortex by inhibiting D-aspartate catabolism (42). Thus, a defective $\mathrm{D}$-aspartate/mGlu5 receptor axis might contribute to the pathophysiology of schizophrenia, and some antipsychotic drugs might reinforce mGlu5 receptor signaling by enhancing endogenous D-aspartate levels. Whether D-aspartate directly activates mGlu5 receptors, or receptor activation is secondary to the enhanced glutamate release induced by $\mathrm{D}$-aspartate remains to be determined.

\section{mGlu5 RECEPTOR PAMS AS NOVEL ANTIPSYCHOTIC AGENTS}

The leading hypothesis of NMDA receptor hypofunction in schizophrenia stems from the strong psychotomimetic effects of slow NMDA receptor channel blockers, such as phenyclidine (PCP) and ketamine, the cognitive dysfunction and psychosis caused by NMDA receptor autoantibodies in patients affected by autoimmune encephalitis and the large body of evidence obtained in mice lacking NMDA receptors or treated with NMDA receptor antagonists. NMDA receptors are found in most CNS neurons; however, they are highly expressed and functional in cortical interneurons (43). Several drugs that activate NMDA receptors have been developed for the treatment of schizophrenia, but with limited success in clinical trials. One notable example is bitopertin, a drug that inhibits the high affinity uptake of the NMDA receptor co-agonist, glycine. After promising preclinical and phase- 2 clinical studies, bitopertin failed in phase- 3 trials (44). Although clinical data with bitopertin were disappointing, active work on NMDA receptor agonists continues. A functional cross-talk exists between mGlu5 and NMDA receptors. Activation of mGlu5 receptors facilitates NMDA receptor function (45-50), whereas activation of NMDA receptors amplifies mGlu5 receptor activity by restraining receptor desensitization (51). This and other observations laid the groundwork for the development of mGlu5 reptor PAMs for the treatment of schizophrenia. Jeff Conn, Carrie Jones, 
Craig Lidsley and their Associates (Vanderbilt University) are actively involved in the design and development of highly selective and brain permeant mGlu5 receptor PAMs, and they are so kind to make their molecules available to the scientific community. PAMs differ from orthosteric agonists because they have no intrinsic efficacy but amplify the action of endogenous glutamate. Thus, PAMs are particularly advantageous from a therapeutical standpoint because their action is activitydependent. Systemic treatment with mGlu5 PAMs corrects the pathological phenotype in pharmacological and genetic models that have predictive validity for antipsychotic treatment, including models of NMDA receptor hypofunction (52-58) (Figure 1). Excitotoxicity mediated by the enhanced NMDA receptor activity is a potential limtation to the use of mGlu5 receptor PAMs in the treatment of schizophrenia. Accordingly, high doses of mGlu5 receptor PAMs may cause seizures and neurotoxicity in rodents $(4,59,60)$. An elegant way to overcome these limitations is the use of biased mGlu5 receptor PAMs that amplify receptor function without recruiting NMDA receptors $(4,5)$. One of these molecules, compound VU0409551, showed antipsychotic-like activity without activating NMDA receptors (5).

Biased mGlu5 PAMs might be particularly helpful in the treatment of patients affected by schizophrenia who are resistant to conventional antipsychotic medication. Our expectation is that these drugs may improve both positive and negative symptoms and exert pro-cognitive effects by restoring the balance between excitation and inhibition in the prefrontal cortex of patients affected by schizophrenia (58). While an early treatment with mGlu5 PAMs might correct the developmental abnormalities associated with schizophrenia (see above), the impact of a late treatment on disease progression cannot be predicted. A large body of evidence suggests that neuroinflammation has a key role in the progressive degeneration of the gray and white matter associated with schizophrenia (61-63). Interestingly, mGlu5 receptors are present in microglial cells, and their activation drives microglia toward an anti-inflammatory phenotype (64-69).

A potential anti-inflammatory effect of mGlu5 PAMs may slow disease progression in the absence of a direct induction of excitotoxic neuronal death. Thus, biased PAMs that enhance mGlu5 receptor activation without potentiating NMDA receptor currents cater the potential to behave as disease modifyiers in schizophrenia. This interesting hypothesis warrants further investigation in animal models of psychosis associated with neuroinflammation.

\section{TARGETING mGlu1 RECEPTORS IN THE TREATMENT OF PSYCHOSIS}

An elegant manuscript describes a novel form of receptorreceptor interaction involving M4 muscarinic acetylcholine receptors and mGlul receptors (70). This interaction might pave the way to novel therapeutic strategies in schizophrenia. M4 receptor activation inhibits striatal dopamine release by enhancing the production of endocannabinoids, which behave as retrograde messengers at dopaminergic nerve terminals. Interestingly, this mechanism requires the co-activation of mGlu1 receptors, which are coupled to $G_{\mathrm{q} / 11}$, and, therefore, have the fisique $d u$ role to enhance the production of endocannabinoids. M4 receptors, which are coupled to $G_{i / o}$, are also able to inhibit D1 receptor signaling, but this function is independent of mGlu1 receptors (70) (Figure 1). Inhibition of dopamine release mediated by mGlul receptors explains the antipsychotic-like activity of selective mGlul PAMs in rodents (70) and holds promise for the treatment of positive symptoms of schizophrenia. Mutations of GRM1 (the gene encoding for the mGlu1 receptor) that reduce mGlu1 receptor signaling have been associated with schizophrenia (71), and mice lacking mGlu1 receptors display a psychotic-like phenotype (72). This suggests that a defective mGlul receptor expression and/or activity might contribute to the striatal dopaminergic hyperactivity associated with schizophrenia, and that mGlu1 receptor PAMs may correct this defect. Of note, co-activation of M4 and mGlu1 receptors selectively inhibits dopamine release in the striatum without affecting dopaminergic transmission in other brain regions. This suggests that mGlu1 receptor PAMs may reduce dopamine release only where is needed, i.e., in the hyperactive meso-striatal system. This is advantageous with respect to most antisychotic agents, which block D2 receptors with no regional discrimination.

The interplay between mGlul and M4 receptors is one of the many examples of functional interactions between $\mathrm{G}_{\mathrm{q} / 11 \text {-coupled }}$ group-I mGlu receptors and other $\mathrm{G}_{\mathrm{i} / \mathrm{o}}$ coupled receptors. In the cerebellum, $\mathrm{GABA}_{\mathrm{B}}$ receptors cooperate with mGlul receptors at the synapses between parallel fibers and Purkinje cells (73). Andrzej Pilc and his Associates (Krakow University, Polland) have described a synergistic effect between mGlu5 and GABA $B$ receptor PAMs in behavioral tests with pharmacological validity for the treatment of positive, negative and cognitive symptoms of schizophrenia (74).

\section{mGlu2 RECEPTORS AND SCHIZOPHRENIA: TO BE OR NO TO BE?}

The study of mGlu2 receptors as druggable targets in schizophrenia has been a leading theme of research in the whole mGlu receptor field in the last two decades. The evidence that compound LY354740 (a potent, selective, and brain permeant mGlu2/3 agonist) was able to reverse behavioral and neurochemical effects of PCP in rats (75) gave the impetus to the development of orthosteric mGlu2/3 receptor agonists or mGlu2 receptor PAMs as novel "non-monoaminergic" antipsychotic agents. mGlu2 receptors are presynaptic receptors that inhibit neurotransmitter release (3). It is believed that mGlu2 receptor activation produces antipsychotic effects by restraining the activity of 5- $\mathrm{HT}_{2 \mathrm{~A}}$ receptors in the frontal cortex. Gerard Marek and his Associates were first to demonstrate that mGlu2 receptors inhibit electrophysiological responses mediated by $5-\mathrm{HT}_{2 \mathrm{~A}}$ receptors $(76,77)$. In the following years, Javier Gonzalez-Maeso and his Associates showed that mGlu2 receptors form a multimeric complex with $5-\mathrm{HT}_{2 \mathrm{~A}}$ receptors 
and negatively modulate $5-\mathrm{HT}_{2 \mathrm{~A}}$ receptor signaling in response to serotonin-like hallucinogenic drugs (78-81). Expression of mGlu2 receptors in the mouse frontal cortex is under the control of $5-\mathrm{HT}_{2 \mathrm{~A}}$ receptors, and repeated administrations of second-generation antipsychotics, which block $5-\mathrm{HT}_{2 \mathrm{~A}}$ receptors, down-regulates the expression of mGlu2 receptors through an epigenetic mechanism mediated by reduced histone acetylation at the GRM2 gene promoter $(82,83)$. Interestingly, mGlu2 receptors are down-regulated in the frontal cortex of mice subjected to prenatal stress $(84,85)$, which models the epigenetic and behavioral modifications associated with schizophrenia $(84,86)$. Not surprisingly, both mGlu2/3 agonists and mGlu2 PAMs display robust antipsychotic-like activity in a variety of behavioral tests (87-90).

The clinical development of the mGlu2/3 agonist, LY404039 (under the form of the oral prodrug, pomaglumetad methionil) is a remarkable example of how translational research in schizophrenia is conditioned by a number of unpredictable variables. Pomaglumetad methionil was as efficacious as olanzapine in improving positive and negative symptoms of schizophrenia in the first phase 2 clinical trial (91) (Figure 1). Treatment with pomaglumetad methionil did not cause the typical adverse effects of antipsychotic drugs, such as extrapyramidal symptoms, increase in body weight, and hyperprolactinemia (91). These findings generated great enthusiasm, demonstrating for the first time the efficacy of a non-monoaminergic agent in the treatment of schizophrenia. Unfortunately, the antipsychotic activity of pomaglumetad methionil was not confirmed in subsequent phase 2 or 3 clinical trials (92-94), and this led to discontinuation of the development program of LY404039 in schizophrenia with negative consequences for the whole mGlu receptor field. However, a metanalysis of all clinical studies showed that pomeglumetad methionil displayed therapeutic efficacy in subgroups of patients who were early-in-disease and had never been treated with $5-\mathrm{HT}_{2 \mathrm{~A}}$ blocking agents (95). Research on the effect of LY404039 in humans is still ongoing, and both pomaglumetad methionil and LY2979165 (the oral prodrug of the selective mGlu2 receptor agonist, 2812223) were found to reduce ketamine-evoked blood oxygenation level dependent (BOLD) MRI signal in healthy subjects (96). It will be interesting to design clinical trials in which $\mathrm{mGlu} 2 / 3$ receptor agonists (or mGlu2 receptor PAMs) are tested in selected populations of patients affected by schizophrenia recruited on the basis of their genetic background, disease course, and history of previous medication. We are in favor of the development of mixed mGlu2/3 agonists or PAMs (rather than selective mGlu2 PAMs) if we consider the potential impact of all these drugs on disease progression. We have evidence that selective activation of mGlu2 receptors may produce neurotoxic effect (97-99) by enhancing the proinflammatory activity of microglia (100-102) or through other mechanisms. In contrast, activation of mGlu3 receptors is consistently neuroprotective through a mechanism of astrocyte-neuronal interaction mediated by the production of neurotrophic factors, such as transforming-growth factor- $\beta 1$ or glial cell-derived neurotrophic factor $(98,103-105)$.

\section{mGlu4 RECEPTORS AS NOVEL TARGETS FOR THE TREATMENT OF SCHIZOPHRENIA}

The study of individual group-III mGlu receptor subtypes in schizophrenia is now facilitated by the availability of brain permeant subtype-selective agents that are suitable for in vivo studies. One of these drugs is compound LSP4-2022, which behaves as a preferential orthosteric agonist of mGlu4 receptors (106). Systemic treatment with LSP4-2022 has been shown to induce antipsychotic-like activity in a number of behavioral tests and to attenuate neurotransmitter release induced by the NMDA receptor antagonist, MK-801 (107, 108). Interestingly, mGlu4 receptors co-operate with other neurotransmitter receptors coupled to $\mathrm{G}_{\mathrm{i} / \mathrm{o}}$ in improving psychotic-like symptoms in mice. Wozniak et al. (108) showed that the antipsychotic-like activity of LSP4-2022 in mice was prevented by pharmacological blockade of 5- $\mathrm{HT}_{1 \mathrm{~A}}$ receptors, whereas sub-threshold doses of LSP4-2022 and the $5-\mathrm{HT}_{1 \mathrm{~A}}$ agonist, 8-hydroxy-dipropylaminotetraline (8OH-DPAT), acted synergistically in producing antipsychotic- like effects. A similar synergism was shown between LSP4-2022 and drugs that activate $\mathrm{GABA}_{\mathrm{B}}$ receptors, although in this case the synergism could only be demonstrated in behavioral tests that model positive symptoms of schizophrenia (107).

A more recent study exended the analysis to the interaction between mGlu4 and M4 muscarinic receptors in an attempt to develop novel pharmacological strategies with good efficacy in improving positive, negative and cognitive symptoms, and good profile of safety and tolerability. A robust effect was seen by combining subactive doses of LSP4-2022 and the selective M4 muscarinic receptor PAM, VU152100, in behavioral tests that model positive, negative, and cognitive symptoms. This combination also reduced $5-\mathrm{HT}_{2 \mathrm{~A}}$-mediated spontaneous excitatory postsynaptic currents in frontal cortical slices, indicating that mGlu4 and M4 receptors cooperate in reducing glutamate release (109). Remarkably, the association of subactive doses of drugs that activate mGlu4 and M4 receptors did not cause motor impairment in mice, suggesting that the functional cross-talk between mGlu4 and M4 receptors can be targeted by new safer antipsychotic agents (Figure 1).

Finally, the study of mGlu4 receptors provides a new potential link beween the kynurenine pathway and schizophrenia. The kynurenine pathway of tryptophan metabolism generates a series of neuroactive componds, including the mGlu4 receptor agonist, cinnabarinic acid (110). We have evidence that cinnabarinic acid inhibits behavioral and biochemical responses to MK-801 at very low doses (111). Cinnabarinic acid is synthesized in very low amounts in the normal brain, but its production increases considerably under conditions of neuroinflammation. A protective activity of endogenous cinnabarinic acid against neuroinflammation (112) and psychotic symptoms (113) might be lost in schizophrenia because of a lower activity of kynurenine monoxygenase (114-116), the enzyme that converts kynurenine into 3-hydroxykynurenine giving rise to all metabolites that lie downstream of 3-hydroxykynurenine. This is certainly a field of great interest that warrants further investigation. 


\section{CONCLUSIONS}

Subtype-selective mGlu receptor ligands offer the opportunity of a precision medicine based pharmacological approach to target multiple domains of the psychopathological spectrum of schizophrenia. For example, patients with mutations of GRM1 or GRM3 genes might benefit from a treatment with mGlu1 and mGlu3 receptor PAMs, respectively, whereas patients who are early in disease or had never been treated with second-generation antipsychotics might respond to mGlu2/3 receptor agonists. The increasing knowledge of the role played by mGlu3 and mGlu5 receptors in the developmental trajectory of GABAergic interneurons might pave the way to an early use of mGlu3 or

\section{REFERENCES}

1. Vita A, De Peri L, Deste G, Barlati S, Sacchetti E. The effect of antipsychotic treatment on cortical gray matter changes in schizophrenia: does the class matter? A meta-analysis and meta-regression of longitudinal magnetic resonance imaging studies. Biol Psychiatry (2015) 78:403-12. doi: 10.1016/j.biopsych.2015.02.008

2. Wang HY, MacDonald ML, Borgmann-Winter KE, Banerjee A, Sleiman P, Tom A, et al. mGluR5 hypofunction is integral to glutamatergic dysregulation in schizophrenia. Mol Psychiatry (2018). doi: 10.1038/s41380-018-0234-y. [Epub ahead of print].

3. Nicoletti F, Bockaert J, Collingridge GL, Conn PJ, Ferraguti F, Schoepp DD, et al. Metabotropic glutamate receptors: from the workbench to the bedside. Neuropharmacology (2011) 60:1017-41. doi: 10.1016/j.neuropharm.2010.10.022

4. Rook JM, Noetzel MJ, Pouliot WA, Bridges TM, Vinson PN, Cho HP, et al. Unique signaling profiles of positive allosteric modulators of metabotropic glutamate receptor subtype 5 determine differences in in vivo activity. Biol Psychiatry (2013) 73:501-9. doi: 10.1016/j.biopsych.2012.09.012

5. Rook JM, Xiang Z, Lv X, Ghoshal A, Dickerson JW, Bridges TM, et al. Biased mGlu5-positive allosteric modulators provide in vivo efficacy without potentiating mGlu5 modulation of NMDAR currents. Neuron (2015) 86:1029-40. doi: 10.1016/j.neuron.2015.03.063

6. Di Menna L, Joffe ME, Iacovelli L, Orlando R, Lindsley CW, Mairesse J, et al. Functional partnership between mGlu3 and mGlu5 metabotropic glutamate receptors in the central nervous system. Neuropharmacology (2018) 128:30113. doi: 10.1016/j.neuropharm.2017.10.026

7. Sladeczek F, Pin JP, Récasens M, Bockaert J, Weiss S. Glutamate stimulates inositol phosphate formation in striatal neurones. Nature (1985) 317:717-9. doi: $10.1038 / 317717 \mathrm{a} 0$

8. Nicoletti F, Iadarola MJ, Wroblewski JT, Costa E. Excitatory amino acid recognition sites coupled with inositol phospholipid metabolism: developmental changes and interaction with alpha 1-adrenoceptors. Proc Natl Acad Sci USA. (1986) 83:1931-5. doi: 10.1073/pnas.83.6.1931

9. Wong FK, Bercsenyi K, Sreenivasan V, Portalés A, Fernández-Otero M, Marín O. Pyramidal cell regulation of interneuron survival sculpts cortical networks. Nature (2018) 557:668-73. doi: 10.1038/s41586-018-0139-6

10. Ben-Ari Y. The GABA excitatory/inhibitory developmental sequence: a personal journey. Neuroscience (2014) 279:187-219. doi: 10.1016/j.neuroscience.2014.08.001

11. Pizzorusso T, Medini P, Berardi N, Chierzi S, Fawcett JW, Maffei L. Reactivation of ocular dominance plasticity in the adult visual cortex. Science (2002) 298:1248-51. doi: 10.1126/science.1072699

12. Ueno H, Suemitsu S, Okamoto M, Matsumoto Y, Ishihara T. Parvalbumin neurons and perineuronal nets in the mouse prefrontal cortex. Neuroscience (2017) 343:115-27. doi: 10.1016/j.neuroscience.2016.11.035

13. Gonzalez-Burgos G, Cho RY, Lewis DA. Alterations in cortical network oscillations and parvalbumin neurons in schizophrenia. Biol Psychiatry (2015) 77:1031-40. doi: 10.1016/j.biopsych.2015.03.010
mGlu5 receptor PAMs as disease modifying agents, being aware that treatment of schizophrenia in the preclinical phase awaits the discovery of predictive biomarkers endowed with high specificity and selectivity. Finally, some mGlu receptor ligands might have a positive impact on neuroinflammation by influencing microglial function or through other mechanisms. There are no reasons to be skeptical and continue to develop new mGlu receptor ligands for the treatment of schizophrenia with good hope of success.

\section{AUTHOR CONTRIBUTIONS}

All authors listed have made a substantial, direct and intellectual contribution to the work, and approved it for publication.

14. Pantazopoulos H, Woo TU, Lim MP, Lange N, Berretta S. 2010. Extracellular matrix-glial abnormalities in the amygdala and entorhinal cortex of subjects diagnosed with schizophrenia. Arch Gen Psychiatry (2010) 67:155-66. doi: 10.1001/archgenpsychiatry.2009.196

15. Berretta S. Extracellular matrix abnormalities in schizophrenia. Neuropharmacology (2012). 62:1584-97. doi: 10.1016/j.neuropharm.2011.08.010

16. Berretta S, Pantazopoulos H, Markota M, Brown C, Batzianouli ET. Losing the sugar coating: potential impact of perineuronal net abnormalities on interneurons in schizophrenia. Schizophr Res (2015) 167:18-27. doi: 10.1016/j.schres.2014.12.040

17. Catania MV, Landwehrmeyer GB, Testa CM, Standaert DG, Penney JB Jr, Young AB. Metabotropic glutamate receptors are differentially regulated during development. Neuroscience (1994) 61:481-95. doi: 10.1016/0306-4522(94)90428-6

18. Notartomaso S, Nakao H, Mascio G, Scarselli P, Cannella M, Zappulla C, et al. mGlu1 receptors monopolize the synaptic control of cerebellar Purkinje cells by epigenetically down-regulating mGlu5 receptors. Sci Rep. (2018) 8:13361. doi: 10.1038/s41598-018-31369-7

19. Luoni A, Gass P, Brambilla P, Ruggeri M, Riva MA, Inta D. Altered expression of schizophrenia-related genes in mice lacking mGlu5 receptors. Eur Arch Psychiatry Clin Neurosci. (2018) 268:77-87. doi: 10.1007/s00406-01 6-0728-Z

20. Battaglia G, Imbriglio T, Verhaeghe R, Martinello K, Del Percio C, Pascarelli MT, et al. Genetic Deletion of mGlu3 Receptors Causes Developmental Abnormalities in GABAergic Neurons and Cortical Neural Synchronization in Mice: A Multi-Modal and -Scale Approach. Program No. 122.05. In: 2018 Neuroscience Meeting Planner. San Diego, CA: Society for Neuroscience (2018).

21. Notartomaso S, Mascio G, Scarselli P, Martinello K, Fucile S, Gradini R, et al. Expression of the $\left.\mathrm{K}^{+}\right) / \mathrm{Cl}\left({ }^{-}\right)$cotransporter, KCC2, in cerebellar Purkinje cells is regulated by group-I metabotropic glutamate receptors. Neuropharmacology (2017) 115:51-59. doi: 10.1016/j.neuropharm.2016.07.032

22. Barnes SA, Pinto-Duarte A, Kappe A, Zembrzycki A, Metzler A, Mukamel EA, et al. Disruption of mGluR5 in parvalbumin-positive interneurons induces core features of neurodevelopmental disorders. Mol Psychiatry (2015) 20:1161-72. doi: 10.1038/mp.2015.113

23. Fujioka R, Nii T, Iwaki A, Shibata A, Ito I, Kitaichi $K$, et al. Comprehensive behavioral study of mGluR3 knockout mice: implication in schizophrenia related endophenotypes. Mol Brain (2014) 23:31. doi: 10.1186/1756-6606-7-31

24. Lainiola M, Procaccini C, Linden AM. mGluR3 knockout mice show a working memory defect and an enhanced response to MK-801 in the T- and Y-maze cognitive tests. Behav Brain Res. (2014) 266:94-103. doi: 10.1016/j.bbr.2014.03.008

25. Corti C, Crepaldi L, Mion S, Roth AL, Xuereb JH, Ferraguti F. Altered dimerization of metabotropic glutamate receptor 3 in schizophrenia. Biol Psychiatry (2007) 62:747-55. doi: 10.1016/j.biopsych.2006.12.005 
26. Fujii Y, Shibata H, Kikuta R, Makino C, Tani A, Hirata N, et al. Positive associations of polymorphisms in the metabotropic glutamate receptor type 3 gene (GRM3) with schizophrenia. Psychiatr Genet. (2003) 13:71-76. doi: 10.1097/01.ypg.0000056682.82896.b0

27. Fijal BA, Kinon BJ, Kapur S, Stauffer VL, Conley RR, Jamal HH, et al. Candidate-gene association analysis of response to risperidone in AfricanAmerican and white patients with schizophrenia. Pharmacogenomics J. (2009) 9:311-18. doi: 10.1038/tpj.2009.24

28. Egan MF, Straub RE, Goldberg TE, Yakub I, Callicott JH, Hariri AR, et al. Variation in GRM3 affects cognition, prefrontal glutamate, and risk for schizophrenia. Proc Natl Acad Sci USA. (2004) 101:12604-609. doi: 10.1073/pnas.0405077101

29. Chen Q, He G, Chen Q, Wu S, Xu Y, Feng G, et al. A case-control study of the relationship between the metabotropic glutamate receptor 3 gene and schizophrenia in the Chinese population. Schizophr Res. (2005) 73:21-6. doi: 10.1016/j.schres.2004.07.002

30. Norton N, Williams HJ, Dwyer S, Ivanov D, Preece AC, Gerrish A, et al. No evidence for association between polymorphisms in GRM3 and schizophrenia. BMC Psychiatry (2005) 13:5-23. doi: 10.1186/1471-244X-5-23

31. Bishop JR, Ellingrod VL, Moline J, Miller D. Association between the polymorphic GRM3 gene and negative symptom improvement during olanzapine treatment. Schizophr Res. (2005) 77:253-60. doi: 10.1016/j.schres.2005.04.001

32. Bishop JR, Wang K, Moline J, Ellingrod VL. Association analysis of the metabotropic glutamate receptor type 3 gene (GRM3) with schizophrenia. Psychiatr Genet (2007) 17:358. doi: 10.1097/YPG.0b013e3281ac231e

33. Bishop JR, Miller del D, Ellingrod VL, Holman T. Association between typethree metabotropic glutamate receptor gene (GRM3) variants and symptom presentation in treatment refractory schizophrenia. Hum Psychopharmacol. (2011) 26:28-34. doi: 10.1002/hup.1163

34. Schwab SG, Plummer C, Albus M, Borrmann-Hassenbach M, Lerer B, Trixler M, et al. DNA sequence variants in the metabotropic glutamate receptor 3 and risk to schizophrenia: an association study. Psychiatr Genet (2008) 18:25-30. doi: 10.1097/YPG.0b013e3282ef48d9

35. Sartorius LJ, Weinberger DR, Hyde TM, Harrison PJ, Kleinman JE, Lipska BK. Expression of a GRM3 splice variant is increased in the dorsolateral prefrontal cortex of individuals carrying a schizophrenia risk SNP. Neuropsychopharmacology (2008) 33:2626-34. doi: 10.1038/sj.npp.1301669

36. Maj C, Minelli A, Giacopuzzi E, Sacchetti E, Gennarelli M. The role of metabotropic glutamate receptor genes in schizophrenia. Curr Neuropharmacol. (2016) 14:540-50. doi: 10.2174/1570159X13666150514232745

37. Saini SM, Mancuso SG, Mostaid MS, Liu C, Pantelis C, Everall IP, et al. Metaanalysis supports GWAS-implicated link between GRM3 and schizophrenia risk. Transl Psychiatry (2017) 7:e1196. doi: 10.1038/tp.2017.172

38. Devon RS, Anderson S, Teague PW, Muir WJ, Murray V, Pelosi AJ, et al. The genomic organisation of the metabotropic glutamate receptor subtype 5 gene, and its association with schizophrenia. Mol Psychiatry (2001) 6:311-14. doi: $10.1038 /$ sj.mp. 4000848

39. Molinaro G, Pietracupa S, Di Menna L, Pescatori L, Usiello A, Battaglia G, et al. D-aspartate activates $\mathrm{mGlu}$ receptors coupled to polyphosphoinositide hydrolysis in neonate rat brain slices. Neurosci Lett. (2010) 478:128-30. doi: 10.1016/j.neulet.2010.04.077

40. Errico F, Napolitano F, Squillace M, Vitucci D, Blasi G, de Bartolomeis A, et al. Decreased levels of D-aspartate and NMDA in the prefrontal cortex and striatum of patients with schizophrenia. J Psychiatr Res. (2013) 47:1432-7. doi: 10.1016/j.jpsychires.2013.06.013

41. Nuzzo T, Sacchi S, Errico F, Keller S, Palumbo O, Florio E, et al. Decreased free d-aspartate levels are linked to enhanced d-aspartate oxidase activity in the dorsolateral prefrontal cortex of schizophrenia patients. NPJ Schizophr. (2017) 3:16. doi: 10.1038/s41537-017-0015-7

42. Sacchi S, Novellis V, Paolone G, Nuzzo T, Iannotta M, Belardo C, et al. Olanzapine, but not clozapine, increases glutamate release in the prefrontal cortex of freely moving mice by inhibiting D-aspartate oxidase activity. Sci Rep. (2017) 7:46288. doi: 10.1038/srep46288

43. Moghaddam B, Javitt D. From revolution to evolution: the glutamate hypothesis of schizophrenia and its implication for treatment. Neuropsychopharmacology (2012) 37:4-15. doi: 10.1038/npp.2011.181
44. Bugarski-Kirola D, Blaettler T, Arango C, Fleischhacker WW, Garibaldi G, Wang A, et al. Bitopertin in negative symptoms of schizophrenia-results from the phase III FlashLyte and DayLyte studies. Biol Psychiatry (2017) 82:8-16. doi: 10.1016/j.biopsych.2016.11.014

45. Doherty AJ, Palmer MJ, Henley JM, Collingridge GL, Jane DE. (RS)2-Chloro-5- hydroxyphenylglycine (CHPG) activates mGlu5, but no mGlu1, receptors expressed in $\mathrm{CHO}$ cells and potentiates NMDA responses in the hippocampus. Neuropharmacology (1997) 36:265-67. doi: 10.1016/S0028-3908(97)00001-4

46. Ugolini A, Corsi M, Bordi F. Potentiation of NMDA and AMPA responses by the specific mGluR5 agonist CHPG in spinal cord motoneurons. Neuropharmacology (1999) 38:1569-76. doi: 10.1016/S0028-3908(99)00095-7

47. Awad H, Hubert GW, Smith Y, Levey AI, Conn PJ. Activation of metabotropic glutamate receptor 5 has direct excitatory effects and potentiates NMDA receptor currents in neurons of the subthalamic nucleus. J Neurosci. (2000) 20:7871-879. doi: 10.1523/JNEUROSCI.20-21-07871.2000

48. Attucci S, Carlà V, Mannaioni G, Moroni F. Activation of type 5 metabotropic glutamate receptors enhances NMDA responses in mice cortical wedges. $\mathrm{Br} J$ Pharmacol (2001) 132:799-806. doi: 10.1038/sj.bjp.0703904

49. Mannaioni G, Marino MJ, Valenti O, Traynelis SF, Conn PJ. Metabotropic glutamate receptors 1 and 5 differentially regulate CA1 pyramidal cell function. J Neurosci. (2001) 21:5925-34. doi: 10.1523/JNEUROSCI.21-16-05925.2001

50. Pisani A, Gubellini P, Bonsi P, Conquet F, Picconi B, Centonze D, et al. Metabotropic glutamate receptor 5 mediates the potentiation of N-methyld-aspartate responses in medium spiny striatal neurons. Neuroscience (2001) 106:579-87. doi: 10.1016/S0306-4522(01)00297-4

51. Alagarsamy S, Saugstad J, Warren L, Mansuy IM, Gereau RW 4th, Conn PJ. NMDA-induced potentiation of mGluR5 is mediated by activation of protein phosphatase 2B/calcineurin. Neuropharmacology (2005) 49 (Suppl. 1):135-45. doi: 10.1016/j.neuropharm.2005.05.005

52. Kinney GG, Burno M, Campbell UC, Hernandez LM, Rodriguez D, Bristow LJ, et al. Metabotropic glutamate subtype 5 receptors modulate locomotor activity and sensorimotor gating in rodents. J Pharmacol Exp Ther. (2003) 306:116-23. doi: 10.1124/jpet.103.048702

53. Kinney GG, O’Brien JA, Lemaire W, Burno M, Bickel DJ, Clements $\mathrm{MK}$, et al. A novel selective positive allosteric modulator of metabotropic glutamate receptor subtype 5 has in vivo activity and antipsychotic-like effects in rat behavioral models. J Pharmacol Exp Ther. (2005) 313:199-206. doi: 10.1124/jpet.104.079244

54. Lecourtier L, Homayoun H, Tamagnan G, Moghaddam B. Positive allosteric modulation of metabotropic glutamate 5 (mGlu5) receptors reverses N-Methyl- D-aspartate antagonist-induced alteration of neuronal firing in prefrontal cortex. Biol Psychiatry (2007) 62:739-46. doi: 10.1016/j.biopsych.2006.12.003

55. Liu F, Grauer S, Kelley C, Navarra R, Graf R, Zhang G, et al. ADX47273 [S-(4-fluoro-phenyl)-\{3-[3-(4-fluoro-phenyl)-[1,2,4]-oxadiazol5 -yl]-piperidin-1-yl\}-methanone]: a novel metabotropic glutamate receptor 5-selective positive allosteric modulator with preclinical antipsychotic-like and procognitive activities. J Pharmacol Exp Ther. (2008) 327:827-39. doi: 10.1124/jpet.108.136580

56. Gastambide F, Gilmour G, Robbins TW, Tricklebank MD. The $\mathrm{mGlu}_{5}$ positive allosteric modulator LSN2463359 differentially modulates motor, instrumental and cognitive effects of NMDA receptor antagonists in the rat. Neuropharmacology (2013) 64:240-47. doi: 10.1016/j.neuropharm.2012.07.039

57. Balu DT, Li Y, Takagi S, Presti KT, Ramikie TS, Rook JM, et al. An mGlu5-Positive allosteric modulator rescues the neuroplasticity deficits in a genetic model of NMDA receptor hypofunction in schizophrenia. Neuropsychopharmacology (2016) 41:2052-61. doi: 10.1038/npp. 2016.2

58. Stansley BJ, Conn PJ. The therapeutic potential of metabotropic glutamate receptor modulation for schizophrenia. Curr Opin Pharmacol. (2018) 38:3136. doi: 10.1016/j.coph.2018.02.003

59. Parmentier-Batteur S, Hutson PH, Menzel K, Uslaner JM, Mattson BA, O'Brien JA, et al. Mechanism based neurotoxicity of mGlu5 
positive allosteric modulators-development challenges for a promising novel antipsychotic target. Neuropharmacology (2014) 82:161-73. doi: 10.1016/j.neuropharm.2012.12.003

60. Conde-Ceide S, Alcázar J, Alonso de Diego SA, López S, MartínMartín ML, Martínez-Viturro CM, et al. Preliminary investigation of 6,7-dihydropyrazolo[1,5-a]pyrazin-4-one derivatives as a novel series of mGlu5 receptor positive allosteric modulators with efficacy in preclinical models of schizophrenia. Bioorg Med Chem Lett. (2016) 26:429-34. doi: 10.1016/j.bmcl.2015.11.098

61. Müller N, Weidinger E, Leitner B, Schwarz MJ. The role of inflammation in schizophrenia. Front Neurosci. (2015) 9:372. doi: 10.3389/fnins.2015.00372

62. Trépanier MO, Hopperton KE, Mizrahi R, Mechawar N, Bazinet RP. Postmortem evidence of cerebral inflammation in schizophrenia: a systematic review. Mol Psychiatry (2016) 21:1009-26. doi: $10.1038 / \mathrm{mp} .2016 .90$

63. Miller BJ, Goldsmith DR. Towards an immunophenotype of schizophrenia: progress, potential mechanisms, and future directions. Neuropsychopharmacology (2017) 42:299-317. doi: 10.1038/npp.2016.211

64. Byrnes KR, Stoica B, Loane DJ, Riccio A, Davis MI, Faden AI. Metabotropic glutamate receptor 5 activation inhibits microglial associated inflammation and neurotoxicity. Glia (2009) 57:550-60. doi: 10.1002/glia. 20783

65. Loane DJ, Stoica BA, Pajoohesh-Ganji A, Byrnes KR, Faden AI. Activation of metabotropic glutamate receptor 5 modulates microglial reactivity and neurotoxicity by inhibiting NADPH oxidase. J Biol Chem. (2009) 284:1562939. doi: $10.1074 /$ jbc.M806139200

66. Piers TM, Heales SJ, Pocock JM. Positive allosteric modulation of metabotropic glutamate receptor 5 down-regulates fibrinogen-activated microglia providing neuronal protection. Neurosci Lett. (2011) 505:140-5. doi: 10.1016/j.neulet.2011.10.007

67. Xue F, Stoica BA, Hanscom M, Kabadi SV, Faden AI. Positive allosteric modulators (PAMs) of metabotropic glutamate receptor 5 (mGluR5) attenuate microglial activation. CNS Neurol Disord Drug Targets (2014) 13:558-66. doi: 10.2174/18715273113126660199

68. Qiu JL, Zhu WL, Lu YJ, Bai ZF, Liu ZG, Zhao P, et al. The selective mGluR5 agonist CHPG attenuates SO2-induced oxidative stress and inflammation through TSG-6/NF- $\mathrm{B}$ pathway in BV2 microglial cells. Neurochem Int. (2015) 85-86:46-52. doi: 10.1016/j.neuint.2015. 04.007

69. Hanak TJ, Libbey JE, Doty DJ, Sim JT, DePaula-Silva AB, Fujinami RS. Positive modulation of mGluR5 attenuates seizures and reduces TNF$\alpha(+)$ macrophages and microglia in the brain in a murine model of virus-induced temporal lobe epilepsy. Exp Neurol. (2018) 311:194-204. doi: 10.1016/j.expneurol.2018.10.006

70. Yohn SE, Foster DJ, Covey DP, Moehle MS, Galbraith J, GarciaBarrantes PM, et al. Activation of the mGlu(1) metabotropic glutamate receptor has antipsychotic-like effects and is required for efficacy of M(4) muscarinic receptor allosteric modulators. Mol Psychiatry (2018). doi: 10.1038/s41380-018-0206-2. [Epub ahead of print].

71. Cho HP, Garcia-Barrantes PM, Brogan JT, Hopkins CR, Niswender CM, Rodriguez AL, et al. Chemical modulation of mutant mGlul receptors derived from deleterious GRM1 mutations found in schizophrenics. ACS Chem Biol. (2014) 17:2334-46. doi: 10.1021/cb500560h

72. Brody SA, Conquet F, Geyer MA. (2003) Disruption of prepulse inhibition in mice lacking mGluR1. Eur J Neurosci. (2003)18:3361-66. doi: 10.1111/j.1460-9568.2003.03073.x

73. Tabata T, Araishi K, Hashimoto K, Hashimotodani $Y$, van der Putten $H$, Bettler $\mathrm{B}$, et al. $\mathrm{Ca}^{2+}$ activity at GABAB receptors constitutively promotes metabotropic glutamate signaling in the absence of GABA. Proc Natl Acad Sci USA. (2004) 101:16952-7. doi: 10.1073/pnas.0405387101

74. Wieronska JM, Kłeczek N, Wozniak M, Gruca P, Łason-Tyburkiewicz M, Papp $\mathrm{M}$, et al. $\mathrm{mGlu}_{5}-\mathrm{GABA}_{\mathrm{B}}$ interplay in animal models of positive, negative and cognitive symptoms of schizophrenia. Neurochem Int. (2015) 88:97-109. doi: 10.1016/j.neuint.2015.03.010

75. Moghaddam B, Adams BW. Reversal of phencyclidine effects by a group II metabotropic glutamate receptor agonist in rats. Science (1998) 281:1349-52. doi: $10.1126 /$ science.281.5381.1349
76. Aghajanian GK, Marek GJ. Serotonin model of schizophrenia: emerging role of glutamate mechanisms. Brain Res Brain Res Rev. (2000) 31:302-12. doi: 10.1016/S0165-0173(99)00046-6

77. Marek GJ, Wright RA, Schoepp DD, Monn JA, Aghajanian GK. 2000. Physiological antagonism between 5-hydroxytryptamine(2A) and group II metabotropic glutamate receptors in prefrontal cortex. J Pharmacol Exp Ther. (2000) 292:76-87.

78. Gonzalez-Maeso J, Ang RL, Yuen T, Chan P, Weisstaub NV, López-Giménez JF, et al. Identification of a serotonin/glutamate receptor complex implicated in psychosis. Nature (2008) 452:93-7. doi: 10.1038/nature06612

79. Gonzalez-Maeso J. Allosteric signaling through an mGlu2 and 5$\mathrm{HT}_{2 \mathrm{~A}}$ heteromeric receptor complex and its potential contribution to schizophrenia. Sci Signal (2016) 9:ra5. doi: 10.1126/scisignal.aab0467

80. Fribourg M, Moreno JL, Holloway T, Provasi D, Baki L, Mahajan R, et al. Decoding the signaling of a GPCR heteromeric complex reveals a unifying mechanism of action of antipsychotic drugs. Cell (2011) 147:1011-23. doi: 10.1016/j.cell.2011.09.055

81. Delille HK, Mezler M, Marek GJ. The two faces of the pharmacological interaction of $\mathrm{mGlu}_{2}$ and $5-\mathrm{HT}_{2 \mathrm{~A}}$ - relevance of receptor heterocomplexes and interaction through functional brain pathways. Neuropharmacology (2013) 70:296e305. doi: 10.1016/j.neuropharm.2013.02.005

82. Kurita M, Holloway T, García-Bea A, Kozlenkov A, Friedman AK, Moreno $\mathrm{JL}$, et al. HDAC2 regulates atypical antipsychotic responses through the modulation of mGlu2 promoter activity. Nat Neurosci. (2012) 15:1245-54. doi: $10.1038 / \mathrm{nn} .3181$

83. de la Fuente Revenga M, Ibi D, Cuddy T, Toneatti R, Kurita M, Ijaz MK, et al. Chronic clozapine treatment restrains via HDAC2 the performance of mGlu2 receptor agonism in a rodent model of antipsychotic activity. Neuropsychopharmacology (2018) 44:443-54. doi: 10.1038/s41386-018-0143-4

84. Matrisciano F, Tueting P, Maccari S, Nicoletti F, Guidotti A. Pharmacological activation of group-II metabotropic glutamate receptors corrects a schizophrenia-like phenotype induced by prenatal stress in mice. Neuro Psychopharmacol. (2012) 37:929-38. doi: 10.1038/npp.2011.274

85. Holloway T, Moreno JL, Umali A, Rayannavar V, Hodes GE, Russo SJ, et al. Prenatal stress induces schizophrenia-like alterations of serotonin $2 \mathrm{~A}$ and metabotropic glutamate 2 receptors in the adult offspring: role of maternal immune system. J Neurosci. (2013) 33:1088-98. doi: 10.1523/JNEUROSCI.2331-12.2013

86. Dong Z, Sun X, Pan C, Lu T, Han Y, Wang L, et al. Association of DISC1, $\mathrm{BDNF}$, and COMT polymorphisms with exploratory eye movement of schizophrenia in a Chinese Han population. Psychiatr Genet (2016) 26:258265 doi: 10.1097/YPG.0000000000000138

87. Field JR, Walker AG, Conn PJ. Targeting glutamate synapses in schizophrenia. Trends Mol Med. (2011) 17:689-98. doi: 10.1016/j.molmed.2011.08.004

88. Fell MJ, McKinzie DL, Monn JA, Svensson KA. Group II metabotropic glutamate receptor agonists and positive allosteric modulators as novel treatments for schizophrenia. Neuropharmacology (2012) 62:1473-83. doi: 10.1016/j.neuropharm.2011.06.007

89. Nikiforuk A, Popik P, Drescher KU, van Gaalen M, Relo AL, Mezler M, et al. Effects of a positive allosteric modulator of group II metabotropic glutamate receptors, LY487379, on cognitive flexibility and impulsivelike responding in rats. J Pharmacol Exp Ther. (2010) 335:665-73. doi: 10.1124 /jpet.110.170506

90. Hiyoshi T, Marumo T, Hikichi H, Tomishima Y, Urabe H, Tamita T, et al. Neurophysiologic and antipsychotic profiles of TASP0433864, a novel positive allosteric modulator of metabotropic glutamate 2 receptor. $J$ Pharmacol Exp Ther. (2014) 351:642-53. doi: 10.1124/jpet.114.218651

91. Patil ST, Zhang L, Martenyi F, Lowe SL, Jackson KA, Andreev BV, et al. Activation of mGlu2 $/ 3$ receptors as a new approach to treat schizophrenia: a randomized Phase 2 clinical trial. Nat Med. (2007) 13:11027. doi: $10.1038 / \mathrm{nm} 1632$

92. Kinon BJ, Potts AJ, Watson SB. Placebo response in clinical trials with schizophrenia patients. Curr Opin Psychiatry (2011) 24:107-13. doi: 10.1097/YCO.0b013e32834381b0 
93. Stauffer VL, Millen BA, Andersen S, Kinon BJ, Lagrandeur L, Lindenmayer JP, et al. Pomaglumetad methionil: no significant difference as an adjunctive treatment for patients with prominent negative symptoms of schizophrenia compared to placebo. Schizophr Res. (2013) 150:434-41. doi: 10.1016/j.schres.2013.08.020

94. Downing AM, Kinon BJ, Millen BA, Zhang L, Liu L, Morozova MA, et al. A double-blind, placebo-controlled comparator study of LY21400 23 monohydrate in patients with schizophrenia. BMC Psychiatry (2014) 14:351. doi: 10.1186/s12888-014-0351-3

95. Kinon BJ, Millen BA, Zhang L, McKinzie DL. Exploratory analysis for a targeted patient population responsive to the metabotropic glutamate $2 / 3$ receptor agonist pomaglumetad methionil in schizophrenia. Biol Psychiatry (2015) 78:754-62. doi: 10.1016/j.biopsych.2015.03.016

96. Mehta MA, Schmechtig A, Kotoula V, McColm J, Jackson K, Brittain $\mathrm{C}$, et al. Group II metabotropic glutamate receptor agonist prodrugs LY2979165 and LY2140023 attenuate the functional imaging response to ketamine in healthy subjects. Psychopharmacology (2018) 235:1875-86. doi: 10.1007/s00213-018-4877-9

97. Corti C, Battaglia G, Molinaro G, Riozzi B, Pittaluga A, Corsi M, et al. The use of knock-out mice unravels distinct roles for mGlu2 and mGlu3 metabotropic glutamate receptors in mechanisms of neurodegeneration/neuroprotection. J Neurosci. (2007) 27:8297-308. doi: 10.1523/JNEUROSCI.1889-07.2007

98. Caraci F, Molinaro G, Battaglia G, Giuffrida ML, Riozzi B, Traficante A, et al. Targeting group II metabotropic glutamate (mGlu) receptors for the treatment of psychosis associated with Alzheimer's disease: selective activation of mGlu2 receptors amplifies beta-amyloid toxicity in cultured neurons, whereas dual activation of mGlu2 and mGlu3 receptors is neuroprotective. Mol Pharmacol. (2011) 79:618-26. doi: $10.1124 / \mathrm{mol} .110 .067488$

99. Motolese, M., Mastroiacovo, F., Cannella, M., Bucci, D., Gaglione, A., Riozzi, B., et al. Targeting type- 2 metabotropic glutamate receptors to protect vulnerable hippocampal neurons against ischemic damage. Mol Brain (2015) 8:66. doi: 10.1186/s13041-015-0158-2

100. Taylor DL, Diemel LT, Cuzner ML, Pocock JM. Activation of group II metabotropic glutamate receptors underlies microglial reactivity and neurotoxicity following stimulation with chromogranin A, a peptide up-regulated in Alzheimer's disease. J Neurochem. (2002) 82:1179-91. doi: 10.1046/j.1471-4159.2002.01062.x

101. Taylor DL, Jones F, Kubota ES, Pocock JM. Stimulation of microglial metabotropic glutamate receptor mGlu2 triggers tumor necrosis factor alpha- induced neurotoxicity in concert with microglial-derived Fas ligand. $J$ Neurosci. (2005) 25:2952-64. doi: 10.1523/JNEUROSCI.4456-04.2005

102. Kaushal V, Schlichter LC. Mechanisms of microglia-mediated neurotoxicity in a new model of the stroke penumbra. J Neurosci. (2008) 28:2221-30. doi: 10.1523/JNEUROSCI.5643-07.2008

103. Bruno V, Battaglia G, Casabona G, Copani A, Caciagli F, Nicoletti F. (1998) Neuroprotection by glial metabotropic glutamate receptors is mediated by transforming growth factor-beta. J Neurosci. (1998) 18:9594600. doi: 10.1523/JNEUROSCI.18-23-09594.1998

104. Battaglia G, Molinaro G, Riozzi B, Storto M, Busceti CL, Spinsanti P, et al. Activation of mGlu3 receptors stimulates the production of GDNF in striatal neurons. PLoS ONE (2009) 4:e6591. doi: 10.1371/journal.pone.00 06591

105. Battaglia G, Riozzi B, Bucci D, Di Menna L, Molinaro G, Pallottino S, et al. Activation of mGlu3 metabotropic glutamate receptors enhances GDNF and GLT-1 formation in the spinal cord and rescues motor neurons in the SOD-1 mouse model of amyotrophic lateral sclerosis. Neurobiol Dis. (2015) 74:126-36. doi: 10.1016/j.nbd.2014.11.012

106. Goudet C, Vilar B, Courtiol T, Deltheil T, Bessiron T, Brabet I, et al. A novel selective metabotropic glutamate receptor 4 agonist reveals new possibilities for developing subtype selective ligands with therapeutic potential. FASEB J. (2012) 26:1682-93. doi: 10.1096/fj.11-1 95941

107. Wozniak M, Acher F, Marciniak M, Lason-Tyburkiewicz M, Gruca $P$, Papp $M$, et al. Involvement of $G A B A B$ receptor signaling in antipsychotic-like action of the novel orthosteric agonist of the mGlu4 receptor, LSP4-2022. Curr Neuropharmacol. (2016) 14:413-26. doi: 10.2174/1570159X13666150516000630

108. Wozniak M, Gołembiowska K, Noworyta-Sokołowska K, Acher F, Cieślik P, Kusek M, et al. Neurochemical and behavioral studies on the 5-HT(1A)-dependent antipsychotic action of the mGlu(4) receptor agonist LSP4-2022. Neuropharmacology (2017) 115:149-65. doi: 10.1016/j.neuropharm.2016.06.025

109. Cieślik P, Wozniak M, Rook JM, Tantawy MN, Conn PJ, Acher F, et al. Mutual activation of glutamatergic $\mathrm{mGlu}_{(4)}$ and muscarinic $\mathrm{M}_{(4)}$ receptors reverses schizophrenia-related changes in rodents. Psychopharmacology (2018) 235:2897-2913. doi: 10.1007/s00213-01 8-4980-y

110. Fazio F, Lionetto L, Molinaro G, Bertrand HO, Acher F, Ngomba RT, et al. Cinnabarinic acid, an endogenous metabolite of the kynurenine pathway, activates type 4 metabotropic glutamate receptors. Mol Pharmacol. (2012) 81:643-56. doi: 10.1124/mol.111.074765

111. Fazio F, Ulivieri M, Volpi C, Gargaro M, Fallarino F. Targeting metabotropic glutamate receptors for the treatment of neuroinflammation. Curr Opin Pharmacol (2018) 38:16-23. doi: 10.1016/j.coph.2018. 01.010

112. Fazio F, Zappulla C, Notartomaso S, Busceti C, Bessede A, Scarselli $\mathrm{P}$, et al. Cinnabarinic acid, an endogenous agonist of type-4 metabotropic glutamate receptor, suppresses experimental autoimmune encephalomyelitis in mice. Neuropharmacology (2014) 81:237-43. doi: 10.1016/j.neuropharm.2014.02.011

113. Fazio F, Ulivieri M, Wieronska JM, Cieślik P, Mascio G, Traficante A, et al. Antipsychotic-like Activity of the Kynurenine Metabolite, Cinnabarinic Acid, in Mice. Program No. 122.07. In: 2018 Neuroscience Meeting Planner. San Diego, CA: Society for Neuroscience (2018).

114. Aoyama N, Takahashi N, Saito S, Maeno N, Ishihara R, Ji X, et al. Association study between kynurenine 3-monooxygenase gene and schizophrenia in the Japanese population. Genes Brain Behav (2006) 5:364-68. doi: 10.1111/j.1601-183X.2006.00231.x

115. Wonodi I, Stine OC, Sathyasaikumar KV, Roberts RC, Mitchell BD, Hong $\mathrm{LE}$, et al. Downregulated kynurenine 3-monooxygenase gene expression and enzyme activity in schizophrenia and genetic association with schizophrenia endophenotypes. Arch Gen Psychiatry (2011) 68:665-74. doi: 10.1001/archgenpsychiatry.2011.71

116. Sathyasaikumar KV, Stachowski EK, Wonodi I, Roberts RC, Rassoulpour A, McMahon RP, et al. Impaired kynurenine pathway metabolism in the prefrontal cortex of individuals with schizophrenia. Schizophr Bull. (2011) 37:1147-56. doi: $10.1093 /$ schbul/sbq112

Conflict of Interest Statement: The authors declare that the research was conducted in the absence of any commercial or financial relationships that could be construed as a potential conflict of interest.

Copyright (c) 2019 Nicoletti, Orlando, Di Menna, Cannella, Notartomaso, Mascio, Iacovelli, Matrisciano, Fazio, Caraci, Copani, Battaglia and Bruno. This is an openaccess article distributed under the terms of the Creative Commons Attribution License (CC BY). The use, distribution or reproduction in other forums is permitted, provided the original author(s) and the copyright owner(s) are credited and that the original publication in this journal is cited, in accordance with accepted academic practice. No use, distribution or reproduction is permitted which does not comply with these terms. 